\title{
MODA NA AUTARQUIA: POLÍTICAS DE MODA NA ITÁLIA FASCISTA NOS ANOS $1930^{1}$
}

\author{
Fashion in Autarchy: politics of fashion in 1930s \\ fascist Italy
}

Alessandra Vaccari $*$

\begin{abstract}
RESUMO
Na segunda metade dos anos 1930, o regime fascista introduziu a autarquia como forma de autonomia econômica da Itália frente às importações de matérias-primas. A autarquia foi lançada como instrumento para responder à crise gerada pelas sanções impostas ao país em 1935 pela Sociedade das Nações após a invasão italiana à Etiópia. $\mathrm{O}$ artigo analisa o papel que a moda teve no programa autárquico lançado pelo regime. Pela sua coação identitária e internacional, a moda permite examinar e colocar em confronto tanto a construção e promoção de uma nova imagem da nação, como as formas de desobediência explícita ou implícita às políticas autárquicas do regime fascista.
\end{abstract}

Palavras-chave: autarquia; moda; Itália

\begin{abstract}
The fascist regime enforced autarchy in the second half of the 1930 s to promote domestic production and reduce raw materials imports. Autarchy was introduced as a strategic response to the economic sanctions that the League of Nations applied to Italy after the Italian invasion of Ethiopia in 1935. The article analyses the role that fashion played in the autarchic programme of the fascist regime. It investigates the relationships that both fascism and fashion have in common with modernism. Particularly, it examines the role that fashion's cultural identity and international
\end{abstract}

\footnotetext{
1 Tradução do texto original em italiano por Débora Russi Frasquete.

* IUAV - Universidade de Veneza
} 
character have played in the construction and promotion of a new national image, as well as fashion-related explicit and implicit forms of disobedience to the autarchic policies of the fascist regime.

Keywords: autarchy; fashion; Italy

\section{Autarquia e moda italiana}

Os regimes totalitários europeus entre as duas guerras - tanto na Alemanha, quanto na Itália - investiram em políticas culturais e econômicas visando promover a nacionalização da moda em aberto antagonismo com a então predominante moda francesa. A autarquia foi na Itália o instrumento protecionista privilegiado pelo regime para potencializar o sistema de moda nacional e para promover um estilo com o qual a nação pudesse identificar-se. ${ }^{2}$

O objetivo declarado do programa autárquico era a autonomia econômica do país, abolindo ou contendo a importação. A autarquia foi lançada pelo regime para responder às sanções comerciais impostas à Itália em novembro de 1935 pela Sociedade das Nações $^{3}$ depois da invasão italiana à Etiópia. Tais sanções se propunham a prejudicar a importação na Itália de materiais úteis à indústria bélica e de minar ao mesmo tempo as exportações.

A autarquia foi também resposta a uma situação de crise na qual os efeitos das sanções de 1935 se misturavam à onda da grande crise de 1929. A autarquia torna-se um leitmotiv do regime que se estendeu até a Segunda Guerra Mundial, muito além das fronteiras cronológicas e simbólicas das sanções. De um ponto de vista cronológico, as sanções permaneceram pouco tempo em vigorapenas até julho de 1936 - e foram desconsideradas por muitos dos

2 Eugenia Paulicelli, L'invenzione del marchio nazionale Italia, in Mario Lupano, Alessandra Vaccari (Org.), Una giornata moderna: moda e stili nell'Italia fascista, Bolonha, Damiani, 2009, p. 280.

3 Organização internacional conhecida também como Liga das Nações que foi fundada depois da Primeira Guerra Mundial e que tinha como objetivo a prevenção de guerras. [N. do T.] 
países que as haviam votado e que, em realidade, continuavam a ter comércio livre com a Itália. De um ponto de vista simbólico, a autarquia representou todas as ambições nacionalistas do regime nos seus esforços de fortalecimento industrial, emancipação criativa e recuperação de uma centralidade cultural.

A meio caminho entre o populismo e o refinamento, a moda desempenhou um papel estratégico na implementação do programa autárquico pela capacidade de agir diretamente sobre os gostos, as ideias e os comportamentos das pessoas, ao mesmo tempo em que soube resistir às utopias estéticas promovidas pelo regime. $\mathrm{O}$ artigo considera esse duplo papel das políticas de moda ${ }^{4}$ na Itália da segunda metade dos anos 1930. Se trata de um duplo papel porque, como sugere Andreas Behnke, o estudo crítico das políticas de moda requer sempre a consideração de aspectos contraditórios, ou seja, "tanto os aspectos violentos, como aqueles sublimes das performances do vestuário que visualizam estruturas de poder, autoridade e agência". 5

Por um lado, pretende-se demonstrar como a política autárquica gerou uma estética imbuída de ideais de beleza metafísica com a tarefa de sublimar a imposição de restrições materiais. Por outro lado, se intenciona refletir como as táticas de reação à autarquia permitiu escapar ao nacionalismo, afastar os medos de provincianismo e alimentar a vocação internacional da moda italiana.

A interpretação autárquica de moda do período fascista amiúde privilegiou as representações oficiais de moda apresentadas pelo regime, por isso estudar as atividades das instituições governamentais e as medidas emitidas para promover uma moda e um estilo italianos se tornou uma oportunidade para conectar, em retrospecto, os sucessos da moda italiana do pós-guerra com as premissas autárquicas de independência criativa e material da moda estrangeira. Neste caminho se colocam pesquisas como as de Sofia Gnoli que deram muita ênfase às políticas governativas de um ponto

4 Sobre o conceito de Políticas de moda ver: Andrea Behnke e Christopher Breward, notas número 5 e 41 , respectivamente.

5 Andreas Behnke, Introduction, Andreas Behnke (Org.), The International Politics of Fashion. Being Fab in a Dangerous World. Popular culture and world politics, Londres, Routledge, 2016, p. 11. 
de vista legislativo, institucional e produtivo, ${ }^{6}$ e aquelas de Eugenia Paulicelli mais atentas ao imaginário associado a tais políticas e a sua recepção por parte do público de moda. ${ }^{7}$

Sem querer propor aqui uma leitura histórica de continuidade entre os anos da autarquia e a história subsequente da moda italiana, interessa todavia refletir por que sua relação com o fascismo faz da moda autárquica um dos aspectos mais conhecidos e estudados. Sobre essa relação, a revisão histórico-crítica começou na Itália após aproximadamente quarenta anos da queda do regime, em 1943. Na ampla mostra Gli annitrenta: arte e cultura in Italia, organizada em Milão em 1982, o tema autarquia foi o centro das atenções da seção dedicada à moda, com curadoria de Alessandra Gnecchi Ruscone. ${ }^{8}$ Datado ao mesmo ano está o livro Il lusso e l'autarchia, escrito pela jornalista de moda Natalia Aspesi, ${ }^{9}$ o primeiro a ser dedicado inteiramente ao tema. $\mathrm{O}$ livro define o fenômeno da moda autárquica e como esse condicionou tanto os aspectos produtivos quanto aqueles midiáticos da moda. Os aspectos propostos variam desde o uso de peles mais baratas, como as de coelho ou de toupeira, para compensar a carência de importações do norte da Europa de peles valiosas como a pele de marta; ao emprego da imagem da realeza e da aristocracia como intérpretes do estilo da nação.

Entre as disciplinas que se dedicaram à investigar moda e autarquia, Elisabetta Merlo destaca a importância da história econômica que relaciona a autarquia com o fortalecimento da indústria têxtil, o protecionismo fascista e a história do capitalismo

6 Sofia Gnoli, La donna, l'eleganza, il fascismo: la moda italiana dalle origini all'Ente nazionale della moda, Catânia, Edizioni del Prisma, 2000; Sofia Gnoli, Eleganza fascista, Roma, Carocci, 2017.

7 Eugenia Paulicelli, Fashion under Fascism: Beyond the Black Shirt, Oxford-Nova Iorque, Berg, 2004.

8 Renato Barilli et al. (Org.), Gli annitrenta: arte e cultura in Italia, Milão, Mazzotta, 1983 [Catálogo da mostra de Milão, Palazzo Reale-Palazzo Arengario e Galleria del Sagrato, 26 janeiro-23 maio 1982]. Entre as primeiras mostras na Itália dedicadas à moda e fascismo: Grazietta Butazzi (Org.), 1922-1943: vent'anni di moda italiana. Proposta per un museo della moda a Milano, Florença, Centro Di, 1980 [Catálogo da mostra de Milão, Museo Poldi Pezzoli, 5 dezembro 1980-25 março 1981]. Rizzoli, 1982.

9 Natalia Aspesi, Il lusso e l'autarchia: storia dell'eleganza italiana 1930-1944, Milão, 
italiano. ${ }^{10}$ Também a história do design industrial dedicou muita atenção à questão autárquica, procurando nela, muitas vezes, as raízes do sucesso do Made in Italy do segundo pós-guerra. Nesse âmbito de investigação um aspecto particularmente examinado é a experimentação em âmbito industrial dos novos materiais autárquicos. ${ }^{11}$ Um exemplo são os substitutos do couro, vendidos com os nomes comerciais de Cuoital, Sapsa e Coriacel, que consistiam em uma mistura de resíduos de couros moídos e amalgamados com látex de borracha. Também fazem parte os tecidos derivados da proteína do leite e da celulose, como aqueles produzidos nas instalações da Snia Viscosa, a mais importante indústria italiana de fibras artificiais e um dos principais exportadores a nível mundial da época.

As abordagens propostas pela história do desenho industrial e pela história econômica tendem a enfatizar os aspectos inovadores do projeto autárquico e a, inconscientemente, apoiar a narrativa fascista nacionalista como resposta criativa da nação às dificuldades materiais causadas pelo bloqueio das importações. E é sempre partindo da ideia de que cada crise força à ação e à inovação, que nos últimos anos a autarquia esteve no centro de uma reinterpretação em termos de sustentabilidade, economia de recursos e formas de autoprodução motivada pela green economy. É esse o caso do livro de Marino Ruzzenenti intitulado L'autarchia verde de 2011 e da mostra realizada à Trienal de Milão em 2014 intitulada Il design italiano oltre le crisi: autarchia, austerità, autoproduzione, na qual a autarquia torna-se o ponto de partida para uma história do design que incorpora o artesanato artístico da década de 1930 e o movimento makers na contemporaneidade. ${ }^{12}$ Nesse sentido, a mostra de Milão se propôs a traçar uma contra-história do design italiano, incidindo a

10 Elisabetta Merlo, Moda italiana: storia di un'industria dall'Ottocento a oggi, Veneza, Marsilio, , 2003.

11 Maura Garofoli (Org.), Le fibre intelligenti: un secolo di storia e cinquant'anni di moda, Milão, Electa, 1991; Federica Dal Falco, Prodotti autarchici 1930-1944. Architettura, design, moda: studi sulla cultura del progetto per la tutela dei beni culturali, Roma, Designpress, 2014.

12 Marino Ruzzenenti, L'autarchia verde: un involontario laboratorio della green economy, Milão, Jaca Book, 2011; Beppe Finessi (Org.), Il design italiano oltre le crisi. Autarchia, austerità, autoproduzione, Mântua, Corraini, 2014. [Catálogo da mostra de Milão, Triennale Design Museum, 4 abril-22 fevereiro 2015]. 
atenção sobre aquilo que esteve ofuscado da grande história do sucesso internacional do Made in Italy do segundo pós-guerra.

\section{As fontes para pesquisa na Itália}

Neste artigo coloca-se em relação aspectos tangíveis e intangíveis da autarquia por meio de um trabalho de análise das fontes, principalmente visuais e textuais, publicadas em âmbito italiano dos anos 1930 até a Segunda Guerra Mundial. O programa autárquico não corresponde, na verdade, somente aos aspectos tangíveis da produção industrial e artesanal de materiais e produtos, mas também e sobretudo aos aspectos intangíveis, com as representações textuais e visuais da autarquia e a maneira na qual essas entram, pela perspectiva nacionalista, na promoção da moda italiana.

As fontes exploradas compreendem revistas de moda, de variedades, de cinema e de trabalhos femininos, catálogos de mostras e eventos promocionais dedicados à moda e patrocinados pelo Estado, publicações oficiais de agências governamentais como o Ente nazionale della moda, arquivos de casas de moda, de agências de imprensa e cinejornais do Istituto Luce. Tais fontes se relevaram úteis para examinar o rico programa propagandístico, composto por mostras, desfiles, concursos e feiras, voltado a sustentar a nacionalização da moda e para refletir sobre os ideais de beleza promovidos pela estética autárquica do fascismo. ${ }^{13}$ [Imagem 1] 


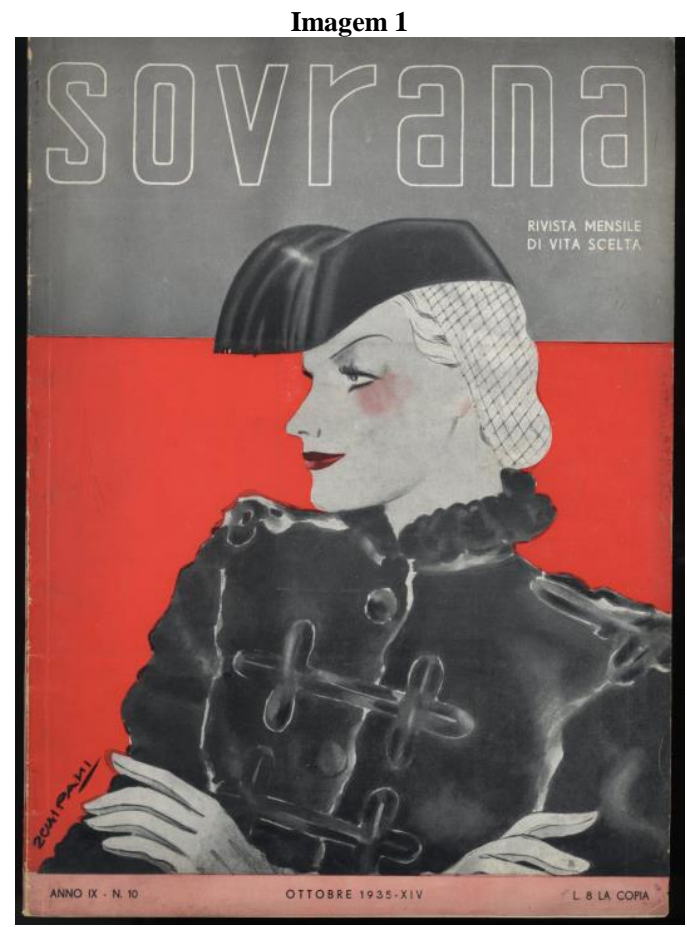

Capa Sovrana, Outubro 1935.

Ressalta-se que o artigo é parte dos resultados de um trabalho de pesquisa, levados adiante pela autora no decorrer dos últimos dez anos e que teve como resultado a publicação dos livros Vestire il ventennio e Una giornata moderna: moda e stili nell'Italia fascista ${ }^{14}$

14 Silvia Grandi, Alessandra Vaccari, Vestire il Ventennio: moda e cultura artistica in Italia tra le due guerre, Bolonha, Bononia University Press, 2004; Mario Lupano, Alessandra Vaccari (Org.), Una giornata moderna: moda e stili nell'Italia fascista [Edição em inglês: Fashion at the Time of Fascism: Italian Modernist Lifestyle Between 1922 and 1943], Bolonha, Damiani, 2009. 
e a curadoria de duas mostras, realizadas respectivamente em Rimini em 2007 e Londres em 2010. ${ }^{15}$

Através do trabalho desenvolvido foi possível recuperar a iconografia da moda italiana desse período, fragmentada em numerosas coleções - de bibliotecas, museus e arquivos - espalhadas por todo o território nacional. Ao contrário de outros países, a Itália não possui grande recolha museal e arquivística centralizada em uma cidade ou na capital, mas uma densa rede de pequenas e grandes coleções. Essa diversidade de acervos cria aos pesquisadores dificuldade de acesso aos materiais, considerando também o atraso na realização dos projetos sistemáticos de digitalização, capazes de criar um diálogo entre os patrimônios de bibliotecas, arquivos e museus italianos. Entre os projetos para favorecer o aproveitamento do patrimônio arquivístico da moda italiana está o portal Archivi della moda del Novecento, inaugurado em 2011 e realizado pela Direzione generale per gli archivi em colaboração com a Associazione nazionale archivistica italiana ${ }^{16}$ e o portal do Sistema archivistico nazionale (San), projeto também inaugurado em 2011 pela Direzione generale per gli archivi, que busca ser um ponto de acesso unificado aos recursos arquivísticos e coordena a integração dos sistemas informáticos de âmbito nacional, regional e local. ${ }^{17}$ Para os recursos bibliotecários destaca-se o portal Internet culturale (IC), com curadoria e direção do Istituto centrale per il catalogo unico delle biblioteche italiane que se propõe a promover a difusão do patrimônio das bibliotecas italianas e oferece também uma seleção de documentos digitalizados e consultáveis como texto completo, embora até o momento ainda em modesta extensão. ${ }^{18}$

15 Ritagli di moda del ventennio, mostra com curadoria de Alessandra Citti e Alessandra Vaccari, Rimini, Museo della città, 25 maio-24 junho 2007; Fashion at the Time of Fascism: Italian Modernist Lifestyle Between 1922 and 1943, mostra com curadoria de Mario Lupano e Alessandra Vaccari, Londres, Fashion Space Gallery, London College of Fashion, 29 abril-28 maio 2010.

$16 \mathrm{http}: / / w w w . m o d a . s a n . b e n i c u l t u r a l i . i t / w o r d p r e s s /$ (Acesso 22 abril 2017). Sobre o argumento ver: Mauro Tosti Croce, Maria Natalina Trivisano, Thematic Portals: Tools for Research and Making the Archival Heritage Known, "Journal of Modern Italian Studies", vol. 20, n. 5, 2015, pp. 732-9.

$17 \mathrm{http}: / /$ san.beniculturali.it/ (Acesso: 21 abr. 2017).

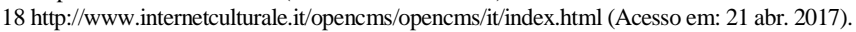




\section{3. $O$ arquivo do Ente nazionale della moda e a sua dispersão}

Entre as dificuldade que encontra quem faz pesquisa sobre a relação entre moda e autarquia está a dispersão do arquivo do Ente nazionale della moda, instituição que o regime criou nos anos 1930 em Turim e que tinha se tornado parte fundamental do programa autárquico. ${ }^{19}$ Na década de sua existência o Ente desenvolveu a tarefa de promover a identidade italiana da moda por meio de ações específicas de propaganda, como a realização de mostras e a publicação de livros e revistas. O Ente se ocupou sobretudo de censurar a influência estrangeira, desenvolvendo específicas formas de controle do trabalho das casas de moda e da indústria têxtil e de vestuário.

Menos conhecido é o fato de que o Ente também propôs a criação de um primeiro centro de documentação sobre a moda italiana em sua própria sede. Tal documentação foi perdida após a dissolução e a liquidação do Ente ocorrida ao final da Segunda Guerra Mundial (decreto legislativo n. 470 de 15 setembro 1946). Com base nas informações recolhidas por Guido Gentile, superintendente no Beni archivistici per il Piemonte e la Valle d'Aosta entre 1978 e 1999, aquilo que restava do arquivo do Ente após a sua dissolução foi encontrado, em torno de 1977-78, em um armazém do governo estadual do Piemonte, na praça Bernini em Turim, no decorrer de uma inspeção feita por ele em conjunto com Bianca Gera, funcionária do ofício de cultura do mesmo governo estadual (Assessorato cultura della Regione Piemonte). Se tratava, segundo Gentile, de livros e de cerca de dez caixas contendo materiais fotográficos. Dos livros descobertos se ocupou Gera, enquanto Gentile fez o requerimento para transportar aquilo que restava do material fotográfico do Ente ao Archivio di Stato di Torino. No período decorrido entre a descoberta do material e a organização do transporte, desapareceram as últimas

19 O Ente nazionale della moda foi instituído com decreto real n. 2084 em 1935 , convertido em lei n. 1424 em 11 maio de 1936, estendendo os objetivos do precedente Ente autonomo per la mostra nazionale permanente della moda de 1932. 
"relíquias de uma lamentável desocupação", segundo a definição utilizada por Gentile e até hoje não se conhece o motivo que levou ao desaparecimento das caixas. ${ }^{20}$

O Ente produziu uma ampla documentação da própria atividade e daquela das empresas e casas de moda italianas que fizeram parte dele na época autárquica. A documentação era conservada em grandes pastas das quais restam apenas algumas imagens que compõem o artigo Come nasce un museo [Imagem 2], publicado em 1938 pelo órgão de informação Bollettino di informazioni dell'Ente nazionale della moda. ${ }^{21}$ As pastas continham fichas técnicas dos modelos enviados pelas casas de moda para obter a chamada Marca di Garanzia, uma certificação de concepção e de produção italianas [Imagem 3]. As fichas, chamadas cartelle, reuniam a fotografia (ou, em alternativa, o desenho) de cada peça acompanhada por amostras de tecido, descrição do modelo, indicação do produtor do tecido e da casa de moda que o havia criado. Outras pastas, também apresentadas no Bollettino, continham as amostras de tecido enviadas para a obtenção da marca Texorit, com o qual o Ente certificava a italianidade ideal e material dos tecidos. A Marca di garanzia e o Texorit foram instituídos pelo Ente respectivamente em 1936 e $1937 .^{22}$ À esses se acrescenta em 1939 a Marca d'oro, certificação que nas intenções do Ente era reservada às criações que se distinguiam pela "originalidade e italianidade da idealização, a nobreza da execução e pelas particulares qualidades técnicas e artísticas". ${ }^{23}$

20 O depoimento inédito de Guido Gentile foi colhido por Sara Micheletta e comunicado à autora via e-mail em 2 de abril 2015 e em 5 de abril 2017.

21 Come nasce un museo, "Bollettino di informazioni dell'Ente nazionale della moda", vol. 3 , n. 19-20, 16 outubro1938, pp. 9-15.

22 Sofia Gnoli, Marca di Garanzia, in Mario Lupano, Alessandra Vaccari (Org.), Una giornata moderna, cit., pp. 286-7.

23 Riunione per la commissione della 'Marca d'Oro', "Rassegna dell'Ente nazionale della moda", vol. 6, n. 5-11, 20 junho 1941, p. 7. 


\section{Imagem 2}

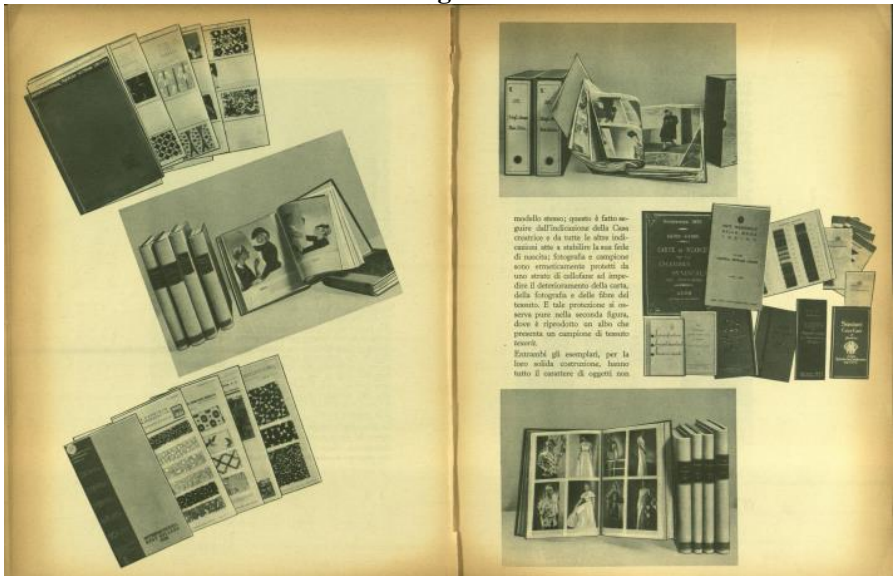

Página dupla, Come nasce un museo, "Bollettino di informazioni dell'Ente nazionale della moda", Outubro 1938.

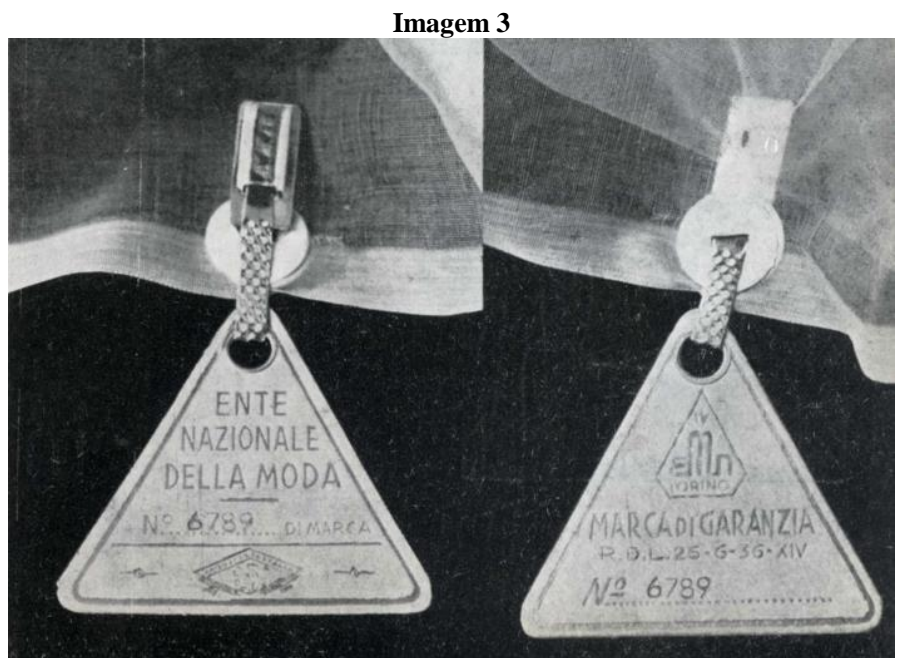

Marca di Garanzia, Ente Nazionale della moda. "Sovrana", Setembro-Outubro 1936. 
Uma parte do arquivo, que pode ser vista nas imagens publicadas no Bollettino, era dedicada a figurinos históricos, entendidos como parte do "patrimônio técnico-literário". ${ }^{4}$ Havia também revistas e materiais ligados à moda estrangeira, recolhidos com a finalidade de comparar as criações italianas com aquelas propostas pelo exterior, para evitar a cópia. Segundo o Bollettino, o material recolhido pelo Ente representava em 1938 o "primeiro passo para a formação de um museu", tendo sido "com cuidado catalogado e classificado" e por fim, paginado "para poder resistir ao tempo". Os acontecimentos porém, demonstraram o contrário.

\section{A mística da autarquia e a metafísica da moda italiana}

Na década de 1930 a autárquica foi teorizada e aplicada em países como os Estados Unidos, o Japão, a Grécia e a Alemanha. No entanto, aquilo que é significativo da experiência italiana é a elaboração de uma mística em torno de uma política econômica baseada na redução de produtos importados e uma pesquisa de substitutos prosaicos para materiais custosos.

O fascismo teorizou a "mística autárquica",26 em paralelo à corrente de pensamento da chamada "mística fascista", baseada no culto da personalidade do duce Benito Mussolini, e no legado da civilização da Roma Antiga. Na "mística autárquica" a autossuficiência produtiva e econômica foi proposta como missão, aventura espiritual de "esplêndido isolamento" 27 e transcendência histórica. ${ }^{28} \mathrm{O}$ filósofo italiano Julius Evola, que foi docente na Scuola

24 Come nasce un museo, cit, p. 10.

25 Ibidem

26 Ernesto Daquanno, Mistica autarchica, Roma, Unione editoriale d'Italia, 1939.

27 Julius Evola [Giulio Cesare Andrea Evola], Fascismo e Terzo Reich, Roma, Edizioni Mediterranee, 2001, p. 88.

28 Massimo Scaligero, Tradizione romanità fascismo, "La Nuova Italia”, n. 540, 22 março 1934 , p. 7. 
di mistica autarchica organizada pelo fascismo, escreve um artigo em 1938 explicando o significado da autarquia em termos de liberação daqueles "povos já despertados a algo espiritual". ${ }^{29}$ Em 1939 Mussolini, também se expressou pela escrita, na introdução do catálogo da Mostra di Leonardo da Vinci e delle invenzioni italiane em Milão. Em seu discurso dizia que "os italianos deveriam criar uma mentalidade autárquica, ou melhor, deveriam viver intensamente na 'mística autárquica"" ${ }^{30}$ A mostra sobre Da Vinci, com curadoria de Giuseppe Pagano, era centralizada no binômio arte-ciência e na promoção do "gênio italiano" por meio do caso exemplar do artista e inventor, utilizado "como a cola ideológica para construir a imagem de uma Itália moderna e industrial".31 A exposição Torino $e$ l'autarchia, de 1938, concebida em estreita ligação com a moda, também dedicou um espaço à "mística autárquica". As salas da mostra se articulavam em torno ao novo Palazzo della moda projetado por Ettore Sottsass sénior ${ }^{32}$ em 1936, inaugurado na ocasião da mostra autárquica ${ }^{33}$, e que era destinado a hospedar os desfiles e as manifestações expositivas sazonais organizadas pelo Ente nazionale della moda, que tinha sede no mesmo palácio.

A autarquia vem proposta como algo em que acreditar, uma inteira ideologia capaz de levar à construção de uma mentalidade autárquica e de dar vida a toda uma estética. Por isso, as restrições materiais impostas pela autarquia foram sublimadas em âmbito têxtil por meio da elaboração de uma linguagem verbal e visual poética e espiritual. Para atuar, a autarquia recorreu à linguagem das vanguardas artísticas, mobilizando tanto o imaginário fictício do Futurismo, quanto a abstração onírica e o efeito de estranhamento da

29 Julius Evola [Giulio Cesare Andrea Evola], Significato spirituale dell'autarchia, (1938), in Id., Fascismo e Terzo Reich, cit., p. 145.

30 Benito Mussolini, [Introduzione], in Mostra di Leonardo da Vinci e delle invenzioni italiane, Milão, 1939. Catálogo da mostra de Milão, Palazzo dell'arte, 9 maio-30 setembro 1939, pp. 2-3.

31 Antonella Huber, La Snia viscosa e il genio italico, in Mario Lupano, Alessandra Vaccari (Org.) Una giornata moderna, cit., p. 274.

32 Ettore Sottsass sénior (Trento, 1892 - Torino 1954) foi um arquiteto italiano e pai do também arquiteto e designer Ettore Sottsass júnior. [N. Do T]

33 La mostra dell'autarchia a Torino, in "La rivista illustrata del Popolo d'Italia", n. 11 novembro 1938, pp. 97-100. A construção de Sottsass senior, ainda existe mesmo que modificada e substituía o precedente Palazzo della moda realizado pelo arquiteto Umberto Cuzzi em 1933. 
metafísica. O caráter visionário e futurista dos novos produtos industriais vem restituído por meio de uma fantasmagoria de nomes comerciais como Acesil, Argentea, Lunesil, Fibrilla, Ivorea $e$ Viscofan, utilizados para promover uma das fibras mais difundidas nesses anos: o rayon. Lanital é o nome com o qual vem comercializada uma fibra têxtil autárquica derivada da caseína (subproduto do processamento do leite) e patenteada por Antonio Carlo Ferretti da Snia Viscosa no início da década de 1930. Para promovê-la, a empresa produtora comissionou em 1937 Il poema del vestito di latte, um livro de artista com gráfica assinada por Bruno Munari com as cores da bandeira italiana; e palavras em liberdade, recurso estilístico literário do fundador do Futurismo Filippo Tommaso Marinetti. ${ }^{34}$

No setor calçadista, a empresa Società anonima lavorazione pelli (Salp) anunciava com o nome evocativo Sirena (sereia) as peles de peixe que deveriam substituir os mais luxuosos répteis exóticos. Para opor-se ao aumento do preço do couro, sobretudo de $1938,{ }^{35}$ se experimentam solas em cunha de cortiça e de madeira pintada, saltos transparentes de vidro e a parte superior feita de materiais baratos torcidos, como a ráfia, a seda e o celofane. Em 1941, quando à autarquia se somavam as restrições da Segunda Guerra Mundial, a revista de previsões de tendências Documento Moda continuava a insistir em materiais alternativos como estopa, madeira, vidro, cortiça e ráfia para o "contributo original" que esses conferiam "à elegância e à moda". ${ }^{36}$

O designer de calçados Salvatore Ferragamo foi um dos principais intérpretes da autarquia e contribuiu de modo determinante para criar sua estética. Os seus escritos autobiográficos restituem o sentimento conflituoso ligado à autarquia: de ressentimento pelo isolamento da Itália e a consequente redução das exportações, mas também de orgulho de haver aprendido a enfrentar as restrições

34 Filippo Tommaso Marinetti, Il poema del vestito di latte: parole in libertà futuriste, Ufficio propaganda della Snia viscosa, [Milão, Tipografia Esperia] 1937.

35 Stefania Ricci, Alla ricerca delle calzature autarchiche, in Lusso \& autarchia: 1935 1945: Salvatore Ferragamo e gli altri calzolai italiani, Livorno, Sillabe, 2005, p. 36 [Catálogo da mostra de Vigevano, Museo internazionale della calzatura, 2005].

36 "Documento moda", vol. 1, n. 1, primavera-verão 1941. 
materiais com respostas criativas originais. Em uma parte de sua autobiografia, citada abaixo, Ferragamo se detém com satisfação a descrever o processo criativo que o levou à invenção, no início da década de 1940, dos famosos sapatos com a parte superior composta de celofane torcido.

Minha mãe adorava os chocolates e naquele dia dei um pulo à loja de doces em frente de casa e comprei uma caixa deles. Enquanto eu desembrulhava um, a embalagem de papel transparente me chamou a atenção. $O$ virei de um lado ao outro entre os dedos: talvez poderia ser o material que eu estava procurando [...] absorvido no meu raciocínio, distraidamente enrolei um pedaço de papel transparente em torno a um dedo até fazer um laço sutil. Puxei e não se rasgou. Estava emocionado: puxei ainda mais forte, depois com toda a força, mas não se rompeu. ${ }^{37}$

É interessante como a relação de Ferragamo está alinhada à retórica da autarquia como temporada criativa da moda italiana, na qual uma descoberta fortuita, como a possiblidade do uso do papel transparente na confecção de calçados, é apresentada como uma intuição na qual convergem genialidade e magia do cotidiano. Os sapatos de celofane foram os precursores da sandália invisível realizada também por Ferragamo com a parte superior trabalhada em fios de nylon, comumente usados em varas de pesca, e graças ao qual o designer receberá nos Estados Unidos, em um contexto político e cultural completamente mudado, o Neiman Marcus Award em 1947. A jornalista italiana Emilia Kuster Rosselli nas páginas da revista de moda Bellezza definiu a sandália invisível de Ferragamo como "sandália metafísica, sandália mágica, sandália que poderia ter sido desenhada por seus dois mundos artísticos opostos, Cassandre ou Milano, Skira, 2010; Brevetto Ferragamo, "Documento moda", vol. 2, n. 2 verão 1942. 
Pisanello". ${ }^{38}$ Portanto, uma sandália entre a gráfica surrealista de Cassandre para Harper's Bazaar e o mundo de conto de fadas do gótico tardio Pisanello. ${ }^{39}$ Não só a sandália de Ferragamo é metafísica, mas também a escrita de Emilia Kuster Rosselli. Comentando essa publicação, Vittoria Caterina Caratozzolo nota como as artes exerceram um papel importante na crítica da moda italiana e como na Itália a "moda é perpetuada pela narrativa exótica que a escrita de moda constrói em torno dessa." ${ }^{40}$ Segundo Breward "as propriedades metafísicas do estilo são uma obsessão perene" ${ }^{41}$ da crítica italiana da arte e do design contemporâneos. Tal obsessão esteve particularmente evidente no projeto de italianização da linguagem de moda promovido pelo fascismo, como o Commentario dizionario italiano della moda publicado em plena época autárquica pelo Ente nazionale della moda. ${ }^{42}$ No Dizionario, os aspectos abertamente nacionalistas e patrióticos estão relacionados - conforme hipótese de Breward - à algo "mais sutil e poético, invocando memória e imaginação como meio de enfatizar as associações nacionais por meio de descrições elevadas de cor, textura e forma". ${ }^{43}$ Esse elemento "mais sutil e poético" se sobrepõe à "mística" da autarquia, que tentava fundar a moda italiana a partir do patrimônio artístico da Itália. O objetivo era de tornar mais lírico e nobre o isolamento forçado da moda francesa e elevar o status dos materiais pobres. Nesse espírito se insere a preparação da Rassegna del tessile e dell'abbigliamento autarchico de Veneza em 1941 com manequins inspirados em de Chirico, projetados pelo arquiteto Erberto Carboni e realizados pela empresa Rosa de Milão. Esses expositores-esculturas haviam perturbadores enxertos de membros humanos e instrumentos musicais. O caráter dessa exibição se alinhava à ideia da boneca-

38 Emilia Kuster Rosselli, Alle origini dell'artigianato fiorentino, "Bellezza", vol. 3, nn. 18-19 maio-junho 1947, p. 3.

39 Cfr. Vittoria C. Caratozzolo, Enchanted Sandals. Italian Shoes and the Post-World War II, in Cristina Giorcelli, Paula Rabinowitz (Org.), Accessorizing the Body: Habits of Being I, Minneapolis, University of Minnesota Press, 2011, p. 232.

40 Vittoria C. Caratozzolo, Enchanted Sandals, cit., nota 12, p. 236.

41 Christopher Breward, The Politics of Fashion. The Politics of Fashion Studies, "Journal of Contemporary History", vol. 42, n. 4 outubro 2007, p. 675.

42 Cesare Meano, Commentario dizionario italiano della moda, Torino, Ente Nazionale della Moda, 1936.

43 Christopher Breward, The Politics of Fashion, cit., p. 675. 
deusa à espera de ser animada pela roupa que veste, imaginada por Massimo Bontempelli em 1925 e com o movimento artístico do Realismo mágico do qual o mesmo foi teórico na Itália. ${ }^{44}$

\section{Desobedecer a autarquia: vocação internacional da moda}

Durante os anos da autarquia a moda sofre vigilância especial devido à sua vocação à abertura internacional, característica que o regime procurou de todas as formas frear. Inibir a importação e a cópia de modelos da haute couture francesa com o objetivo declarado de promover a criatividade e a indústria da moda italiana foi, como já mencionado, um dos principais objetivos do Ente nazionale della moda. Uma produção de moda inteiramente italiana se torna uma utopia a sustentar, como se lê no item Moda in Italia no anteriormente citado Commentario dizionario italiano della moda.

É óbvio que o percentual mínimo de modelos italianos, os quais serão estabelecidos de tempos em tempos, sofrerão variações graduais em relação ao progressivo sucesso da atividade italiana, de modo que não é excluído, ou melhor, é provável, para um não tão distante futuro, o alcance de uma produção nacional totalitária, ou seja, de extensão do requerimento da marca di garanzia à todas as coleções de nossos produtores. ${ }^{45}$

O texto de Meano faz referência ao elaborado mecanismo de certificação da italianidade na criação e ao "percentual" obrigatório dos modelos de concessão italiana - ou seja, de modelos não copiados 
das criações da haute couture francesa- que foram introduzidas pelo Ente por meio da Marca di garanzia. Como desejava Meano no texto citado, o objetivo era alcançar os $100 \%$ graças à autarquia, contudo no momento da introdução da Marca tal percentual era de 25\%; enquanto os restantes $75 \%$ poderiam ser importações. A autarquia como uma forma de controle totalitário para a moda, além de afetar as importações e as produções têxteis e do vestuário, se propunha a regular o consumo, o estilo, os corpos, os gestos e também a linguagem dos italianos. As vestimentas, os discursos dos funcionários governamentais, os editoriais de moda e as fotografias publicitárias nas revistas, oferecem a quem estuda a moda da época autárquica uma infinidade de traços para entender a resistência e as formas de oposição ao programa autárquico.

Quanto às roupas, formas de dissidência e desobediência civil são encontradas tanto por parte dos profissionais do sistema de moda, quanto por parte dos consumidores. Por meio da observação direta dos objetos de vestuário produzidos pelas casas de moda italianas nos anos de autarquia, Laura Zaccagnini e Caterina Chiarelli notam como são raras as peças encontradas com a Marca di Garanzia. ${ }^{46}$ A Marca consistia em uma certificação em papel e em uma etiqueta com as indicações de número que distinguia cada modelo reconhecido exclusivamente como italiano pelo Ente. Cada casa de moda deveria conservar a certificação em papel no próprio arquivo e deveria atar a relativa etiqueta à peça antes de entregá-la ao cliente. Aproximadamente um quarto das peças de vestuário de produção italiana de época autárquica deveria assim, portar tal etiqueta. A sua relativa raridade constitui uma evidência material do que já é conhecido a partir de fontes escritas dos anos 1930 e que corresponde à ideia de que a moda internacional continuava a exercer um grande fascínio seja sobre as casas de moda, seja sobre o público. As casas de moda teriam assim evitado costurar a etiqueta nos modelos que haviam idealizado, dando a ilusão de que fossem franceses; os

46 Laura Zaccagnini com Caterina Chiarelli, Camicetta, scheda del catalogo n. 33, in Caterina Chiarelli (Org.) Moda femminile tra le due guerre, Livorno, Sillabe, 2000, p. 100 [Catálogo da mostra de Florença, Galleria del costume di Palazzo Pitti, 21 junho 2000-21 março $2001]$. 
clientes teriam removido as etiquetas dos modelos que compraram para eliminar os traços de italianidade.

Das declarações dos dirigentes do Ente nazionale della moda emerge como o público estava cético em relação ao programa autárquico. No catálogo da mostra Torino e l'Autarchia, organizada pela Federazione dei Fasci di Combattimento de Turim, Cesare Giriodi Panissera di Monastero, presidente do Ente Nazionale della Moda a partir de outubro de $1938,{ }^{47}$ lamenta por exemplo a persistência da dependência italiana da moda de outras nações. Tal dependência, explica, "tenta resistir e durar" e "ainda hoje um ótimo produto italiano se vê algumas vezes ultrapassado por um produto inferior, mas estrangeiro, precisamente porque é estrangeiro, favorito" ${ }^{48}$ Giriodi Panissera propõe uma visão da autarquia como bonifica ${ }^{49}$ isto é, como purificação da moda italiana das influências estrangeiras no vestuário, não apenas em relação aos materiais (matérias e produtos têxteis nacionais), mas também a nível "moral e artístico". As chamadas operações de bonífica deveriam compreender também aspectos técnicos projetuais da moda, como as previsões de tendências e as relativas cartelas de cor. O Ente, em colaboração com a Azienda colori nazionali affini (Acna), havia já começado em 1933 a publicar a Cartella ufficiale colori italiana que era distribuída gratuitamente aos operários do setor para apresentar as tendências cromáticas italianas, em aberto contraste com as "cartelas estrangeiras" "até não muitos anos atrás consideradas insubstituíveis" $" 50$ segundo Giriodi Panissera.

Infelizmente não existe nenhuma pesquisa sistemática para entender qual e quanta haute couture francesa foi publicada nas revistas de moda italianas nos anos da autarquia. Para quem possuía condições econômicas, Paris continuava a ser a meta mais desejável

47 Cfr. Conferma in carica del presidente dell'Ente Nazionale della Moda per il triennio 1942-1944, “Gazzetta Ufficiale del Regno d'Italia”, a. 83, n. 28, 2 fevereiro 1942, pp. 484-5.

48 Cesare Giriodi Panissera di Monastero, Corporazione dell'abbigliamento, in Torino e l'Autarchia, 1939, p. 41 [Catálogo da mostra de Turim, outubro 1938-novembro 1939].

$49 \mathrm{Em}$ italiano o termo bonifica se refere às operações de drenagem de uma zona úmida e improdutiva, de pântanos, a fim de obter uma porção maior de terras cultiváveis e habitáveis. O termo é aplicado de forma metafórica por Giriodi Panissera, recordando a política de drenagem de zonas úmidas implementada na Itália pelo regime fascista. [N. do T]

50 Ibidem 
para comprar o guarda-roupa. Em alternativa, os modelos franceses podiam ser adquiridos nas casas de moda italianas que haviam pagado por seu direito de reprodução. As mais importantes do período eram Ventura, Marta Palmer, Fumach-Medaglia, Giovanni T. Fercioni, Sandro Radice, Gabriellasport, Biki, Fernanda Lamma, Sorelle Botti, Giovanni Montorsi, Nicola Zecca e Luigi Bigi. As revistas de moda continuavam a ser uma fonte de informação insubstituível sobre as criações francesas, embora com alguns truques para escapar das medidas de real censura por parte do regime. A partir da metade dos anos 1930 as revistas de moda italianas já começam a omitir os nomes das Maisons francesas, comportamento que se torna generalizado a partir de $1937 .^{51}$

As imagens da moda francesa porém, continuaram a ser publicadas, como esclarece a autodenúncia feita em 1938 por Ester Lombardo, diretora da revista Vita femminile. Em resposta à censura de um número de sua revista na qual havia publicado oito imagens de moda francesa, Lombardo escreve abertamente que a compra de fotografias de moda estrangeira das agências internacionais era frequente, colocando-se em aberta polêmica com o Ente nazionale della moda e acusando-o de não ser capaz de superar a carência crônica na Itália de "fotografias de moda que possam diretamente interessar à uma publicação". 52

Com mais frequência, como já dito, as revistas de moda contornavam os obstáculos impostos pela autarquia publicando sem créditos as imagens dos modelos franceses. Assim, em dezembro de 1936, La Donna publicou o célebre tailleur folha de Elsa Schiaparelli sem nominar nem a criadora de moda, nem o autor da fotografia. $\mathrm{O}$ tailleur folha se tornou um ícone da moda do século XX graças aos cliques do fotógrafo Cecil Beaton. ${ }^{53}$ Schiaparelli fazia aberta oposição ao regime, mas enquanto designer de origem italiana, manteve viva a relação cultural e comercial com casas de moda, clientes e revistas italianas. Também uma criação de Schiaparelli e sem créditos consta

51 Cfr. Sofia Gnoli, Eleganza fascista, cit.

52 Ester Lombardo, Consuntivo di una polemica, "Vita femminile", marzo 1938, pp. 9-10. Cit. in Sofia Gnoli, Eleganza fascista, cit., p. 131. Cfr. Natalia Aspesi, Il lusso e l'autarchia, cit. p. 106.

53 Alessandra Vaccari, Elsa Schiaparelli e l'Italia, Mario Lupano, Alessandra Vaccari (Org.), Una giornata moderna, cit., p. 251. 
na fotografia publicada na revista Lidel em novembro de 1935 [Imagem 4]. Além do chapéu e da echarpe cruzada, é inequívoca também a locação onde a fotografia foi tirada. A modelo aparece apoiada à grade de ferro batido do andar nobre do Hôtel de Fontpertuis, número 21 da Place Vendôme, o endereço parisiense no qual, também em 1935, Schiaparelli havia inaugurado a sua nova sede.

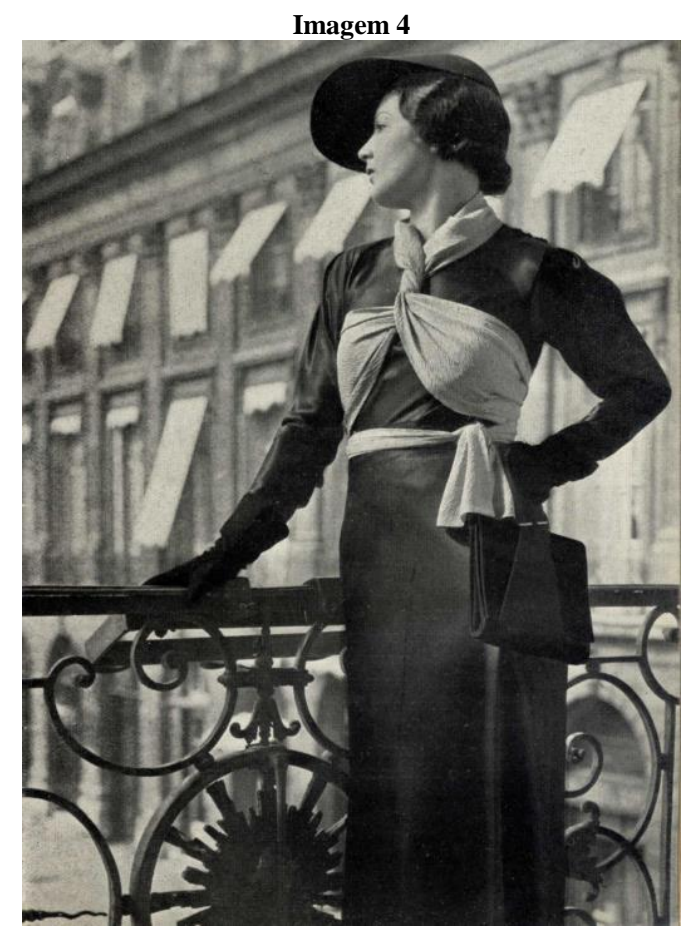

Modelo vetindo um modelo de Elsa Schiaparelli. "Lidel", Novembro 1935. A foto registra a modelo no terraço da Maison da estilista, localizada na Place Vêndome, 12 em Paris, mas foi publicada sem identificação na "Lidel".

Como o exemplo de Schiaparelli demonstra, aprofundar a pesquisa sobre a presença da moda internacional na imprensa italiana seria um exercício fascinante e necessário na medida em que permitiria compreender aspectos centrais das políticas de moda do 
período em oposição à autarquia; concentrar-se melhor na iconografia italiana da moda do período e tornar explícito o contributo da haute couture francesa. Embora consciente da dificuldade de tal pesquisa, essa permitiria a saída da ingenuidade histórica, ainda presente atualmente, de considerar como italiano todos os modelos publicados nas revistas italianas daquele período.

\section{Conclusão}

A moda foi um dos elos mais sensíveis do programa autárquico lançado pelo regime com o objetivo de construir uma nova imagem da nação. A autarquia foi proposta como solução para resolver uma crise econômica, mas sobretudo uma suposta crise moral e estética derivada da paixão italiana pela moda internacional. Com essa intenção, o artigo isolou alguns rastros da autarquia no vestuário, nas revistas, nas imagens de moda, nos discursos do regime e dos profissionais do setor. Por meio desses rastros analisou-se de forma complementar as políticas de moda: de um lado o esforço do regime para dar vida a uma estética da moda italiana capaz de sublimar os aspectos constritivos da autarquia; de outro a reação do sistema industrial da moda e dos seus consumidores às limitações materiais e culturais da troca com o exterior, e em particular com a França. O artigo evidenciou como a moda foi na Itália um dos setores mais expostos às instâncias protecionistas do regime, mas também uma área na qual são manifestadas formas generalizadas de resistência e desobediência civil. Assim, o artigo possibilita pensar como a autarquia contribuiu para reforçar uma estética e uma imagem metafísica da moda italiana e como o fascismo não conseguiu isolar a moda e fazê-la perder o caráter internacional que essa tem em sua natureza.

RECEBIDO EM: 01/03/2017 APROVADO EM: 10/07/2017 